\title{
Dimensionamento geotécnico de uma estrutura de contenção utilizando software
}

O presente trabalho teve como objetivo realizar o dimensionamento geotécnico da contenção do subsolo do Prédio de Engenharias II da Universidade Federal do Maranhão, localizado no Campus Bacanga, São Luís - MA. A região do subsolo a ser contida possui $6 \mathrm{~m}$ de altura e $38 \mathrm{~m}$ de largura. A partir das investigações geotécnicas executadas por meio de sondagens à percussão foi traçado um perfil estratigráfico estimado do terreno e por meio de correlação com o NSPT foram determinados os parâmetros do solo utilizados nos cálculos de pressões atuantes. Devido à altura, adotou-se como solução técnica a cortina atirantada. Para a determinação dos esforços nas ancoragens, utilizou-se o software geotécnico GEO5. A partir do dimensionamento dos tirantes foram realizadas as análises de estabilidade interna e externa. Ambas apresentaram fator de segurança satisfatório.

Palavras-chave: Contenção; Cortina atirantada; Análise de estabilidade.

\section{Geotechnical design of a retaining structure using software}

The present work had the objective of geotechnical design of the subsoil's retaining structure of the Engineering Building II of the Federal University of Maranhão, located at the Bacanga Campus, São Luís - MA. The subsoil region to be contained is $6 \mathrm{~m}$ high and $38 \mathrm{~m}$ wide. From the geotechnical investigations carried out by means of drilling to the percussion an estimated stratigraphic profile of the terrain was drawn, and through correlation with the NSPT the soil parameters used in the calculations of the working pressures were determined. Due to the height, it was adopted as technical solution of anchored wall. Geotechnical software GEO5 was used to determine the anchoring efforts. From the dimensioning of the tight, internal and external stability analyzes were performed. Both presented a satisfactory safety factor

Keywords: Containment; Anchored wall; Stability analysis.

Topic: Engenharia Geotécnica

Reviewed anonymously in the process of blind peer.
Received: 04/03/2021

Approved: 22/03/2021
Rodrigo da Cruz de Araujo (iD)

Universidade Federal do Maranhão, Brasil

http://lattes.cnpq.br/2600077439764627

http://orcid.org/0000-0002-1937-3128

rodrigocruzaraujo@gmail.com

Amanda Morais de Oliveira

Universidade Federal do Maranhão, Brasil

http://lattes.cnpq.br/3597237546811100

amanda morais23@hotmail.com

Mikhail Luczynski iti

Universidade Federal do Pará, Brasil

http://lattes.cnpq.br/3809927360236310

http://orcid.org/0000-0003-0704-9782

mikhail.luczynski@ufma.br
Referencing this:

ARAUJO, R. C.; OLIVEIRA, A. M.; LUCZYNSKI, M.. Dimensionamento geotécnico de uma estrutura de contenção utilizando software. Revista Ibero Americana de Ciências Ambientais, v.12, n.3, p.224237, 2021. DOI: http://doi.org/10.6008/CBPC21796858.2021 .003 .0020 


\section{INTRODUÇÃO}

A preocupação em ocupar novos espaços, decorrente do aumento populacional e de fatores como a saturação do tráfego, valorização dos terrenos e a limitação da altura das construções pelas entidades municipais, levam a uma necessidade de se ter um melhor aproveitamento do espaço subterrâneo e, consequentemente, de escavar subsolos cada vez mais profundos (SILVA, 2011).

A maneira mais simples de suportar uma escavação é por meio da inclinação dos taludes da escavação sem o uso de qualquer suporte. Porém, em meio urbano, onde o espaço para construção é limitado, exige-se o uso de estruturas de contenção, que permitam taludes verticais e, consequentemente, um máximo aproveitamento do espaço (PRADO, 2008). Somado a isso, a realização de grandes obras de infraestrutura com rodovias, ferrovias, túneis e pontes exige que grandes volumes de cortes e aterros sejam executados, e, como consequência direta, que os cortes sejam contidos (MACHADO et al., 2016).

Em áreas de encostas, a execução de estruturas de contenção para a realização de um empreendimento, mesmo abrangendo uma extensão relativamente pequena, pode significar um ônus financeiro muito significativo, e pode em alguns casos, apresentar custo maior que a edificação a ser construída (LUIZ, 2014).

Diante disto, ressalta-se a importância de sempre se desenvolver um projeto que atenda a segurança necessária ao empreendimento com menores custos envolvidos. Prado (2008) destaca que o dimensionamento de uma estrutura de contenção de terra é uma das áreas da engenharia e construção que exige grande domínio, pois requer uma adequada estimativa das características dos terrenos e das ações circundantes, e uma adequada percepção do funcionamento dos elementos estruturais.

A motivação da realização deste estudo surgiu da percepção de que atualmente ainda são encontrados na literatura poucos trabalhos relativos a estruturas de contenções na cidade de São Luís, juntamente com a importância de se fazer um correto dimensionamento deste tipo de estrutura, que, além do ponto de vista econômico, quando em ruína, pode ocasionar perdas materiais e ainda resultar em perdas de vidas humanas.

Nesse contexto, o trabalho tem como objetivo verificar a opção de uma estrutura de contenção mais viável para um determinado caso, elaborando seu dimensionamento geotécnico por meio do uso de softwares.

\section{REVISÃO TEÓRICA}

Os métodos de análise de estabilidade de taludes são divididos em duas categorias: métodos determinísticos, nos quais a medida da segurança do talude é feita em termos de um fator de segurança; e métodos probabilísticos, nos quais a medida de segurança é feita em termos da probabilidade ou do risco de ocorrência da ruptura (DUTRA, 2013). No presente trabalho serão abordados apenas os métodos determinísticos, que consistem nos métodos mais comumente utilizados.

Nesses métodos, com base no conhecimento das forças atuantes determinam-se as tensões de 
cisalhamento induzidas por meio das equações de equilíbrio. A relação entre essa resistência cisalhante disponível (S) e a tensão cisalhante atuante ou resistência mobilizada $(\tau)$ é definida como coeficiente de segurança, o qual deve ser maior à medida que se aumente o grau de incertezas referentes aos parâmetros do solo, custos de recuperação, e perda de vidas humanas.

As análises determinísticas de estabilidade de talude geralmente são feitas por meio dos métodos de equilíbrio-limite, que se baseiam na hipótese de haver equilíbrio numa massa de solo, tomada como um corpo rígido-plástico, na iminência de entrar em processo de escorregamento (MASSAD, 2010).

Para a análise utilizando os métodos do equilíbrio-limite, segundo Massad (2010), adotam-se as seguintes hipóteses:

i) A superfície potencial de ruptura é previamente conhecida e ocorre ao longo de uma superfície bem definida;

ii) A massa de solo se comporta como material rígido-plástico e se encontra em condições iminentes de ruptura generalizada, ou seja, rompe bruscamente sem se deformar;

iii) As equações de equilíbrio estático são válidas até a iminência da ruptura do talude, ou seja, no estado onde a resistência da massa de solo é igual solicitação imposta a ele;

iv) O fator de segurança, FS, é constante ao longo da superfície potencial de ruptura, ignorando-se eventuais fenômenos de ruptura progressiva.

A observação dos escorregamentos na natureza levou as análises a considerar a massa de solo como um todo (Método do Círculo de Atrito), ou subdividida em lamelas ou "fatias" (Método Sueco), ou ainda em cunhas (Método das Cunhas) (MASSAD, 2010).

\section{Teorias de dimensionamento de empuxo de Terra}

Empuxo de terra consiste na ação horizontal produzida por uma maciço de solo sobre a superfície com ele em contato (GERSCOVICH, 2010). É a resultante das tensões provocadas pelo peso próprio do solo e por cargas aplicadas sobre ele, fazendo com que a estrutura em contato com o solo desempenhe papel de contenção para resistir a estes esforços (LUIZ, 2014). Moliterno (1980) resume empuxo de terra como sendo o esforço exercido pela terra contra a estrutura de contenção.

Segundo Luiz (2014), a distribuição de tensões e o consequente valor do empuxo dependem da interação solo-estrutura, mais especificamente da magnitude e sentido do deslocamento da estrutura. Sendo assim, o empuxo é classificado em ativo, passivo ou em repouso.

É considerado empuxo ativo (EA) quando o solo exerce esforço contra a estrutura, empurrando-a. Ao reagir contra esta ação de afastamento da estrutura de contenção, ocorre no solo uma diminuição das tensões horizontais $\left(\sigma^{\prime} h\right)$ até o limite plástico, provocando uma resistência ao longo do possível plano de escorregamento (LUIZ, 2014). No empuxo passivo (EP) a estrutura se desloca contra o solo. O solo é comprimido pela estrutura, sofrendo uma compressão na cunha instável, gerando, assim, ao longo do plano de ruptura, uma reação ao arrastamento denominada resistência ao cisalhamento (BOWLES, 1982, citado por MOTA, 2008).

Quando não há deslocamentos horizontais, o estado do solo é chamado de estado de repouso. Nesse 
caso, a relação entre e tensão efetiva horizontal $\left(\sigma_{h}\right)$ e a tensão efetiva vertical $\left(\sigma_{v}\right)$ é chamada de coeficiente de empuxo no repouso $\left(\mathrm{K}_{0}\right)$.

A distribuição de tensões horizontais nos estados ativo, passivo e em repouso pode ser observada na Figura 1.

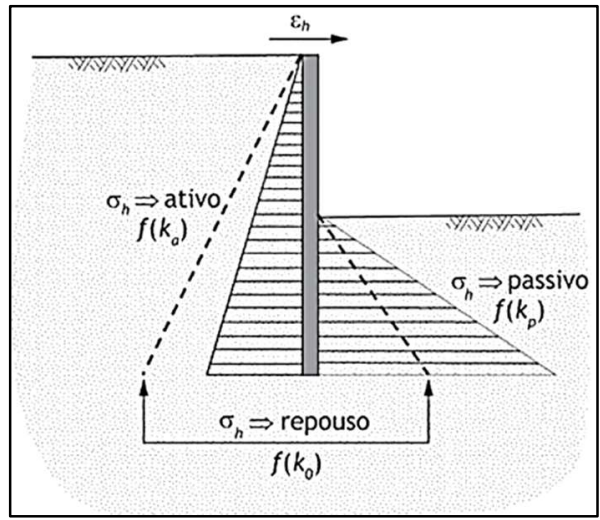

Figura 1: Empuxo em uma estrutura de contenção. Fonte: Gerscovich et al. (2016).

Os cálculos de empuxo ativo e passivo são usualmente resolvidos pelas teorias de estados limite de ruptura. Este trabalho abordará as teorias de dimensionamento de empuxo de Rankine e Coulomb que se baseiam na teoria de equilíbrio limite, ou seja, consideram que o solo esteja em condição de ruptura, situação de total mobilização da resistência ao cisalhamento do solo.

\section{Cortinas atirantadas}

Estruturas de contenção ou de arrimo são obras de engenharia construídas com a finalidade de fornecer estabilidade contra a ruptura aos maciços de terra ou rocha, cuja condição de equilíbrio foi alterada por algum tipo de escavação, corte ou aterro, evitando o escorregamento provocado pelo seu peso próprio ou por carregamentos externos (BARROS, 2008). São utilizadas quando se deseja manter um desnível na superfície do terreno, e as características do solo não permitem que seja executado um talude estável com a inclinação desejada.

Para desníveis elevados, a solução de cortina em balanço não seria adequada, uma vez que seriam necessários comprimentos excessivos de ficha para garantir a estabilidade da cortina. Junto a isso, tanto os esforços quanto os deslocamentos da parede, e consequentemente os recalques nas estruturas vizinhas, também seriam elevados. Nesses casos, recomenda-se a adoção de apoios posicionados em um ou mais níveis ao longo do trecho livre da cortina (GERSCOVICH et al., 2016).

A cortina atirantada consiste em uma estrutura de contenção composta por uma parede de concreto armado e de tirantes ancorados no terreno. Tirantes consistem em elementos estruturais que trabalham a tração, implantados no terreno por meio de uma perfuração e consolidados no solo por meio de injeções de nata de cimento para posteriormente serem protendidos (JOPPERT JUNIOR, 2007). São tracionados, por macaco hidráulico, até uma carga definida em projeto e fixados na parede de concreto por meio de um sistema de placas e porcas (GERSCOVICH et al., 2016).

O paramento de concreto armado, em geral, é dimensionado como laje lisa. Segundo Turcarelli 
(2013), para concreto projetado ou cortinas feitas com fôrmas a espessura usual varia entre $15 \mathrm{~cm}$ a $40 \mathrm{~cm}$, enquanto para parede diafragma, por ser escavada com Clam Shell, costuma ter espessura entre 30 e 120 $\mathrm{cm}$. Essa espessura é definida em função do puncionamento e dos momentos ao longo do painel (GERSCOVICH et al., 2016).

O projeto de cortinas atirantada deve contemplar duas verificações: de estabilidade externa por meio da avaliação do plano de ruptura do talude, e de estabilidade interna por meio da verificação da ruptura da cunha solicitada pelo tirante (TURCARELII, 2013).

O projeto geotécnico de uma cortina atirantada consiste em determinar: a geometria de cada painel, as cargas que atuarão nos tirantes, a inclinação dos tirantes, o comprimento de cada trecho livre, o comprimento dos trechos ancorados, os espaçamentos entre os tirantes, assim como o tipo de fundação que será adotada para cada painel (GERSCOVICH et al., 2016).

\section{METODOLOGIA}

Para a elaboração de um projeto de contenção, é necessário identificar as camadas do subsolo que possam vir a participar dos estudos de estabilidade, assim como determinar suas características geológicas geotécnicas. Segundo a NBR 11682 (ABNT, 2009), "podem ser utilizados quaisquer tipos de investigação que forneçam elementos confiáveis para a montagem do modelo de análise, tanto sob o ponto de vista geométrico como paramétrico".

Gerscovich et al. (2016) ressalta que na prática da engenharia grande parte das estruturas de contenção são projetadas com base em informações obtidas por meio das sondagens a percussão com circulação de água SPT (Standard penetration test).

A determinação de parâmetros de resistência com base na sondagem SPT é realizada por meio de correlações existentes na bibliografia. Schnaid et al. (2012) salientam a necessidade de corrigir a medida Nspt, levando em conta a energia de cravação, antes de utilizar uma correlação internacional.

São diversas as maneiras de se relacionar o índice de resistência à penetração (NSPT) com as características do solo. Diversos autores nacionais e internacionais apresentam correlações e métodos semiempíricos e empíricos que permitem obter os parâmetros geotécnicos do solo em função do NSPT. Neste trabalho, foram utilizadas as correlações apresentadas por Joppert Junior (2007).

\section{Dimensionamento de cortinas atirantadas}

O projeto geotécnico de uma cortina atirantada consiste em determinar: a geometria de cada painel, as cargas que atuarão nos tirantes, a inclinação dos tirantes, o comprimento de cada trecho livre, o comprimento dos trechos ancorados, os espaçamentos entre os tirantes, assim como o tipo de fundação que será adotada para cada painel (GERSCOVICH et al., 2016). Dentre os vários métodos de dimensionamento de cortinas ancoradas, será abordado neste trabalho o método clássico que é baseado na teoria de equilíbrio limite, o qual assume como hipóteses: a cortina é perfeitamente rígida; a cortina sofre apenas deslocamentos de rotação e translação; os empuxos laterais atuantes sobre a cortina são totalmente mobilizados, isto é, os 
empuxos ativo e passivo limites; o solo é rígido perfeitamente plástico. A Figura 2 ilustra a distribuição de empuxos e os deslocamentos assumidos no cálculo.

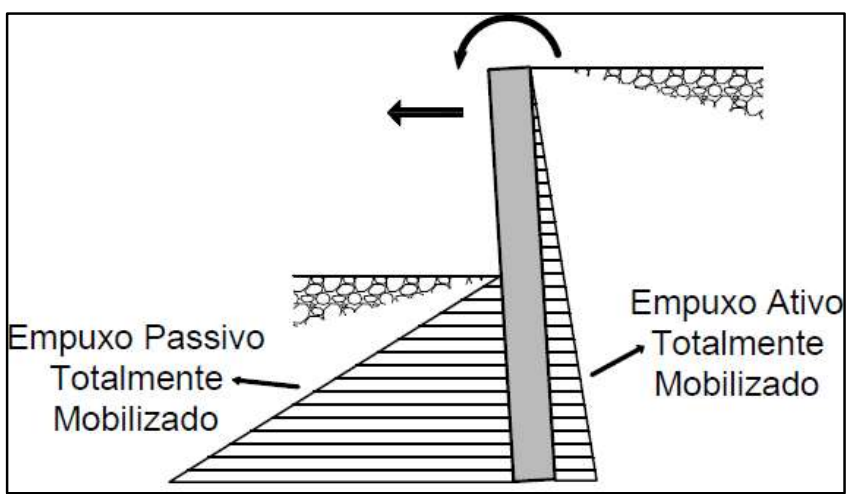

Figura 2: Empuxos e deslocamentos assumidos no cálculo. Fonte: Magalhães (2015).

Por meio das equações de equilíbrio, o método fornece a altura total da estrutura, as cargas nos apoios (tirantes e escoras) e os esforços na estrutura (momento fletor e cortante). Para se obter a solução, são realizadas simplificações de forma a tornar as estruturas de contenção, geralmente hiperestáticas, em uma "viga contínua" isostática.

Os diagramas de forças internas são obtidos do mesmo modo de uma viga isostática, assim, o dimensionamento da cortina pode ser realizado considerando os valores máximos de momento fletor e a força cisalhante. Com base no valor da força no apoio, as escoras ou ancoragens (tirantes) também são dimensionados.

A distribuição dos empuxos considerada corresponde às condições limites, ou seja, quando a cortina está à beira da ruptura por rotação. As tensões atrás da parede estão com os mínimos valores possíveis (limite ativo), enquanto as tensões na frente da cortina estão com seus máximos valores possíveis (limite passivo).

Existem duas metodologias dentro do método clássico: o método da base livre (Free Earth Support) e o método da base engastada (Fixed Earth Support). Basicamente, a diferença entre essas metodologias é a consideração ou não do "engastamento" na base da estrutura de contenção. Essas teorias foram elaboradas considerando um nível de apoio, porém, para cortinas rígidas (por exemplo, paredes moldadas in loco) os métodos de base livre e base engastada podem ser estendidos a cortinas com vários níveis de apoio (GERSCOVICH et al., 2016). Para cortinas em balanço, pode-se apenas desconsiderar os apoios (MOTA, 2008).

No método da base livre considera-se que a cortina tenha rigidez suficiente para girar em torno do ponto de ancoragem, desenvolvendo tensões passivas na frente da cortina e ativas atrás da cortina (GERSCOVICH et al., 2016).

No método da base engastada, a ficha é longa o suficiente para prover uma restrição efetiva às deformações e rotação da cortina (GERSCOVICH et al., 2016). Deste modo, apresenta momento negativo na extremidade inferior da cortina, e momento nulo onde a linha elástica muda de curvatura. 


\section{Dimensionamento do paramento de concreto armado}

O painel de concreto armado foi dimensionado como laje lisa conforme o modelo de cálculo de pórtico equivalente apresentado na NBR 6118 (ABNT, 2014). Após definir o carregamento, utilizou-se o software Ftool para obter os diagramas de esforços internos, e assim realizar a distribuição de momentos segundo faixas internas e externas segundo os critérios: $45 \%$ dos Momentos Positivos para as duas faixas internas; $27,5 \%$ dos Momentos Positivos para cada uma das faixas externas; $25 \%$ dos Momentos Negativos para as duas faixas internas; $37,5 \%$ dos Momentos Negativos para cada uma das faixas externas.

\section{Software GEO5}

O software comercial GEO5, desenvolvido pela empresa FINE Engineering Software Ltd. da República Tcheca, mais precisamente os módulos 'Projeto de contenções' e 'Verificação de contenções' foi utilizado no presente trabalho.

O módulo 'Projeto de contenções' permite que o dimensionamento seja realizado tanto pelo método de base livre como também pelo método da base engastada. $O$ empuxo ativo $\left(E_{a}\right)$ no software é calculado pelo método de Coulomb.

O módulo 'Verificação de contenções' foi utilizado para análises de estabilidade interna e externa. A estabilidade externa no software é realizada pelos métodos de equilíbrio limite.

A estabilidade interna é determinada para cada linha de ancoragem de forma independente. A análise determina uma força de ancoragem, que equilibra o sistema de forças atuantes em uma cunha de ruptura, cuja superfície é formada pelo contorno da contenção, terreno, linha que une a base da estrutura com o bulbo da ancoragem e por uma linha vertical que atravessa o centro do bulbo da ancoragem e do terreno. A análise é executada para um metro de desenvolvimento da estrutura de contenção.

A solução do equilíbrio para uma dada cunha implica definir as equações de equilíbrio para as forças verticais e horizontais. Estas representam um sistema de duas equações, tendo como incógnitas a reação do subsolo Qi e valor máximo permitido para a força de ancoragem Fi.

Como resultado, o programa obtém o valor máximo permitido para a força de ancoragem, para cada linha de ancoragens. Estes valores são comparados com os definidos previamente para as ancoragens.

\section{Estudo de Caso}

O caso analisado trata-se de uma contenção para a implantação do subsolo do Instituto de Engenharia II da Universidade Federal do Maranhão localizado no Campus Bacanga da cidade de São LuísMA. O esboço em planta do prédio e a localização da contenção estão ilustrados na Figura 3.

Neste trabalho, será considerado para o dimensionamento apenas o trecho da contenção localizado no limite entre o térreo e o subsolo. Este trecho apresenta $38,40 \mathrm{~m}$ de comprimento e $6 \mathrm{~m}$ de altura. A investigação geotécnica disponível consistiu em cinco furos de sondagem à percussão (SPT) distribuídos pelo terreno objeto de estudo como indicado na Figura 4. 


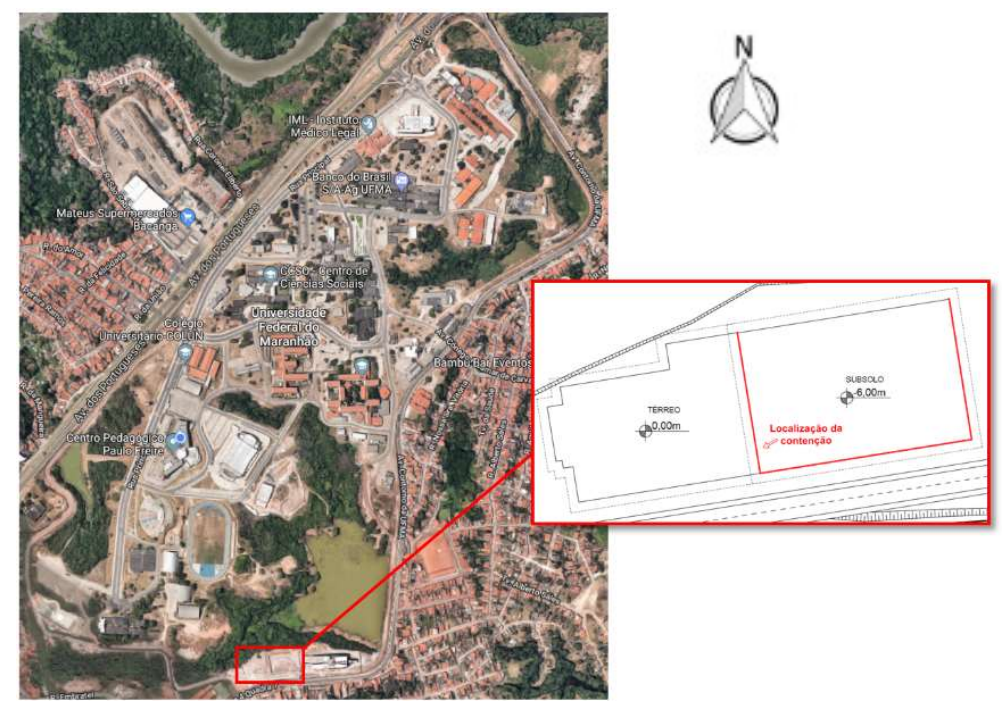

Figura 3: Localização do Instituto de Engenharia II dentro da Universidade Federal do Maranhão - Campus Bacanga. Fonte: Adaptado de Google Earth.

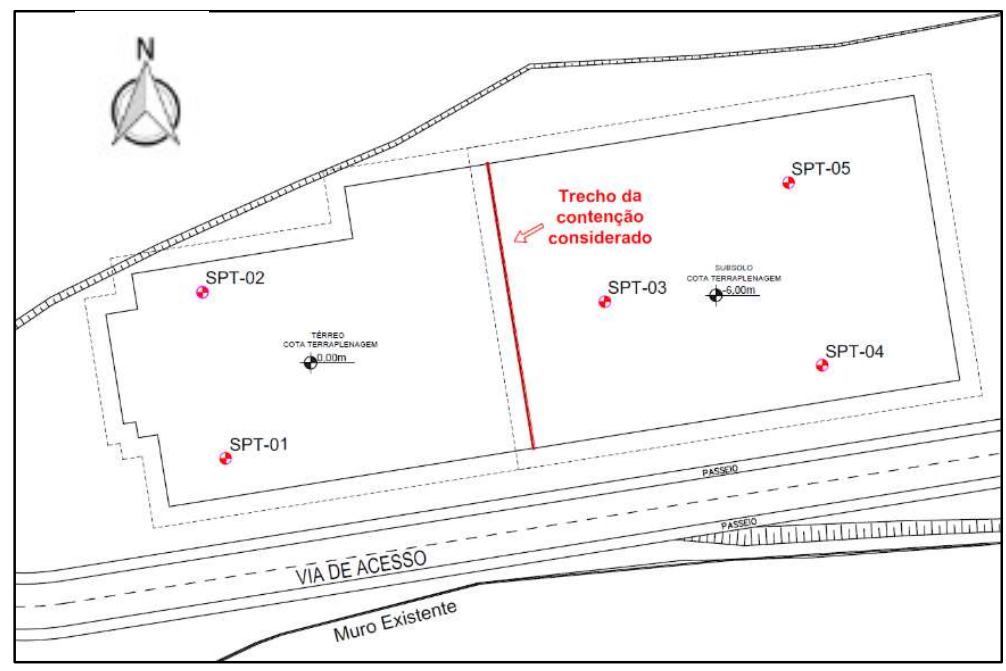

Figura 4: Planta de locação dos furos de sondagem.

O perfil do furo SPT-02 (Figura 5) foi adotado para base na análise e dimensionamento, pois se apresentou geotecnicamente mais adverso (menores valores de NSPT médio por camada).

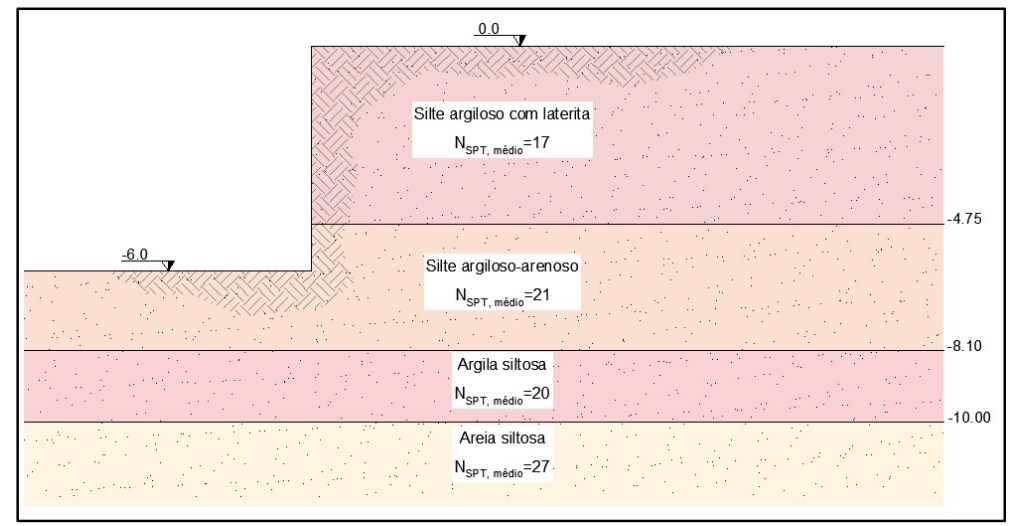

Figura 5: Perfil estratigráfico adotado.

Com base nas correlações apresentas por Joppert Junior (2007), e após aplicar os fatores de segurança recomendados pela NBR 6122 (ABNT, 2010), foram adotados os seguintes parâmetros para os solos considerados (Tabela 1). 
Tabela 1: Parâmetros adotados.

\begin{tabular}{llllll}
\hline Solo & $\gamma\left[\mathrm{kN} / \mathrm{m}^{3}\right]$ & $\mathrm{c}[\mathrm{kPa}]$ & $\varphi\left[^{\circ}\right]$ & $\mathrm{E}[\mathrm{Mpa}]$ & $\mathrm{V}$ \\
\hline Silte argiloso com laterita & 19 & 13 & 19 & 10 & 0,30 \\
\hline Silte argilo-arenoso & 20 & 20 & 20 & 150 & 0,30 \\
\hline Argila siltosa & 20 & 27 & 18 & 30 & 0,30 \\
\hline Areia siltosa & 20 & 0 & 27 & 105 & 0,35 \\
\hline
\end{tabular}

Segundo Gerscovich et al. (2016), é comum utilizar uma sobrecarga uniformemente distribuída de $10 \mathrm{kN} / \mathrm{m}^{2}$ representando carregamento devido a veículos de rua, construção e maquinário de obra. A autora recomenda ainda, caso exista fundações vizinhas que transmitam as cargas ao maciço de solo no trecho da cortina, a utilização de uma carga vertical distribuída, na faixa correspondente a área construída, de $10 \mathrm{kN} / \mathrm{m}^{2}$ para cada pavimento.

Desta forma, será considerada uma sobrecarga de $10 \mathrm{kN} / \mathrm{m}^{2}$ na etapa de execução da primeira linha de ancoragem que ocorrerá durante a fase da obra, e de $40 \mathrm{kN} / \mathrm{m}^{2}$ no final da execução da segunda linha de tirantes correspondente aos 4 pavimentos do Instituto de Engenharia II, que representa o carregamento permanente.

\section{RESULTADOS E DISCUSSÃO}

Devido à grande altura, a possibilidade de utilização de muros de arrimo foi descartada. Uma vez que a contenção se localiza próxima à estrutura do prédio em questão, adotou-se a solução de cortina atirantada, pois, como visto na revisão bibliográfica, esse tipo de contenção apresenta baixos deslocamentos.

\section{Dimensionamento dos tirantes}

Foram consideradas duas fileiras de tirantes, com inclinação de $25^{\circ}$, posicionados a $1,5 \mathrm{~m}$ e $4,5 \mathrm{~m}$ a partir do topo da cortina. Tal inclinação foi adotada de forma a garantir que o cobrimento de terra na primeira fileira de tirantes seja superior a $5 \mathrm{~m}$ como exigido pela NBR5629 (ABNT, 2006).

As forças necessárias nos tirantes foram calculadas pelo software GEO5 - módulo projeto de contenções, utilizando o método da base livre, utilizado para fichas curtas. Foi considerado o empuxo agindo atrás da cortina como empuxo em repouso e o empuxo passivo agindo à frente da cortina calculado pelo método de Coulomb foi minorado em $50 \%$.

Analisando a estrutura, sem o uso de tirantes, para atender a situação permanente $(q=40 \mathrm{kN})$ a ficha necessária para estabilizar o talude seria de 12,84 m, e o momento máximo agindo na cortina seria 2089,54 $\mathrm{kN} . \mathrm{m} / \mathrm{m}$ (Figura 6), o que reforça que sem o uso de tirantes essa alternativa seria inviável, tanto pela grande quantidade de concreto demandado, quanto pela armadura necessária devido ao alto valor de momento fletor.

Após inserir a primeira linha de ancoragem (T1) considerando sobrecarga q=10kN (supondo que será implantada antes do início da execução dos quatro pavimentos) obteve-se esforço na ancoragem de 217,97 kN. Observa-se também a diminuição dos esforços sobre a cortina como se pode ver na Figura 7. 


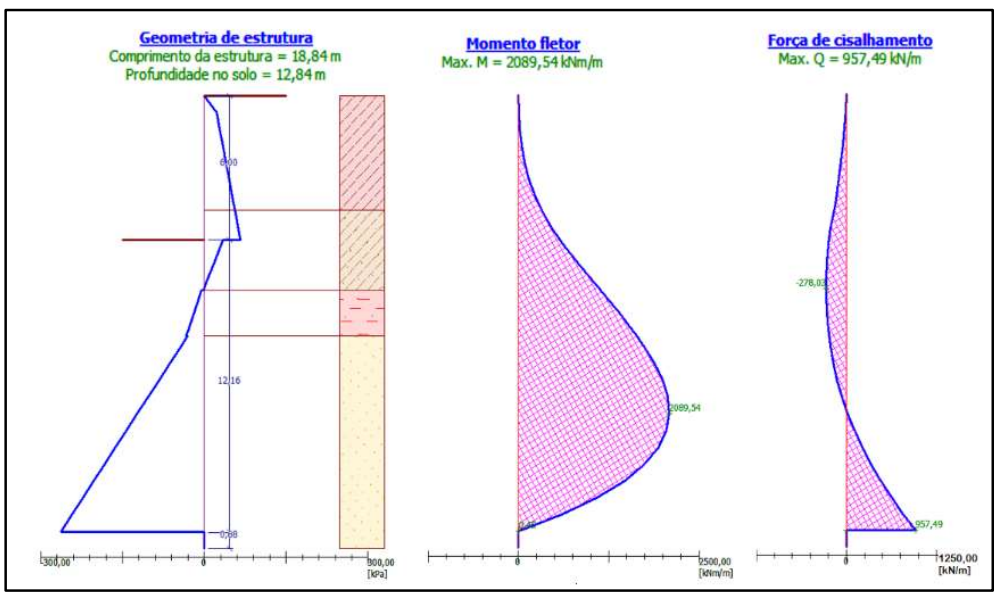

Figura 6: Comprimento da estrutura (sem os tirantes).

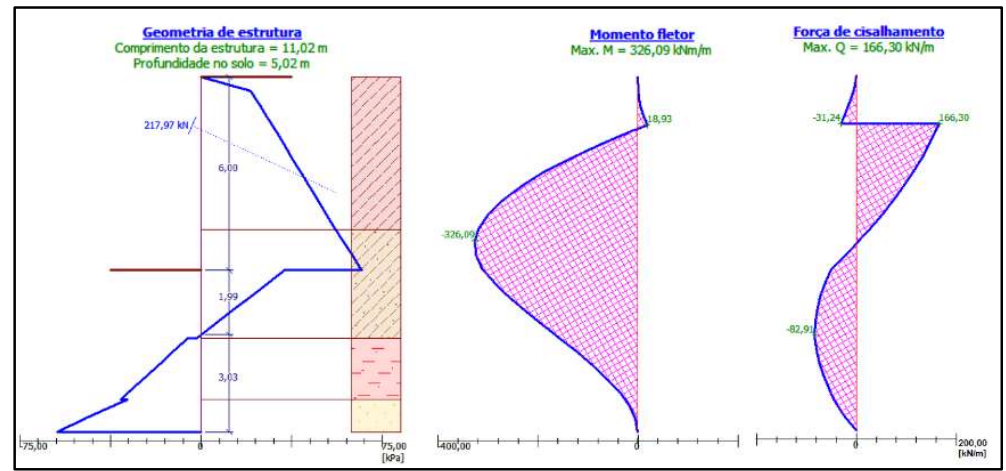

Figura 7: Comprimento da estrutura e carga para a primeira linha de tirantes.

Ao final da segunda linha de ancoragem (T2), para a situação referente ao final da obra ( $q=40 \mathrm{kN})$, o esforço na segunda linha de ancoragem foi de $206,50 \mathrm{kN}$ e o da primeira diminuiu para $81,61 \mathrm{kN}$ (Figura 8 ).

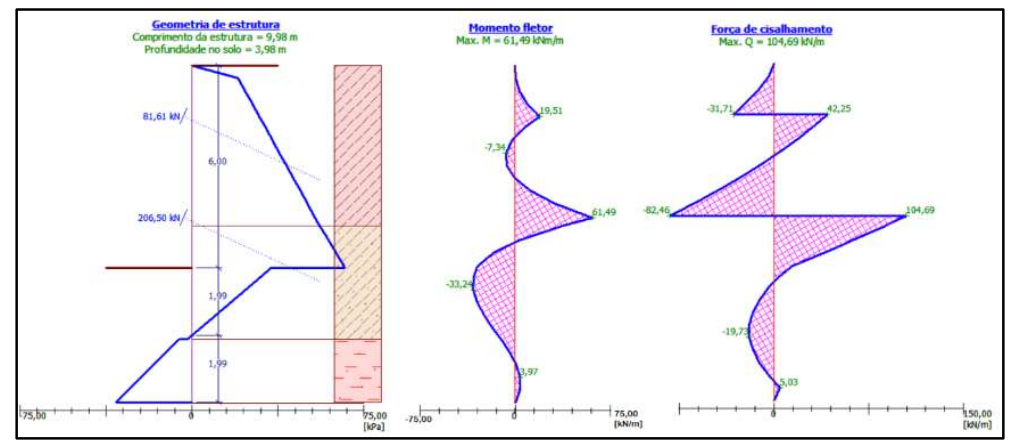

Figura 8: Comprimento da estrutura e carga para primeira e segunda linha de tirantes.

As cargas calculadas pelo GEO5 consistem em forças por metro. Desta forma, os valores fornecidos pelo software devem ser multiplicados pela distância horizontal entre os tirantes. Considerando os maiores valores para cada tirante e adotando a distância horizontal entre os tirantes igual a 1,6 $\mathrm{m}$, os resultados foram 348,75 kN $(217,97 \times 1,6)$ e $330,4 \mathrm{kN}(206,50 \times 1,6)$ para a primeira e segunda linha de tirante, respectivamente. Para o dimensionamento, a carga de trabalho adotada para os tirantes foi de $350 \mathrm{kN}$.

Optou-se por usar um tirante tipo monobarra, que conforme Joppert Junior (2007), para trabalho permanente, deve ser usado o ST 85/105 de $32 \mathrm{~mm}$.

GeoRio (2014) apresenta algumas indicações de comprimentos do bulbo em função do tipo de solo e da carga de trabalho do tirante. Seguindo tais recomendações adotou-se o comprimento de ancoragem de 
8 (oito) metros para ambos os tirantes.

Para o comprimento livre, de modo a garantir que as tensões transmitidas ao solo por meio do bulbo de ancoragem não ocasionem significativos aumentos da pressão de contato sobre a cortina, e que o bulbo esteja além da superfície crítica de deslizamento, foi adotado 7 (sete) metros para a primeira fileira de tirantes e 5 (cinco) metros para a segunda.

Desta forma, o projeto dos tirantes ficou como ilustrado na Figura 9.

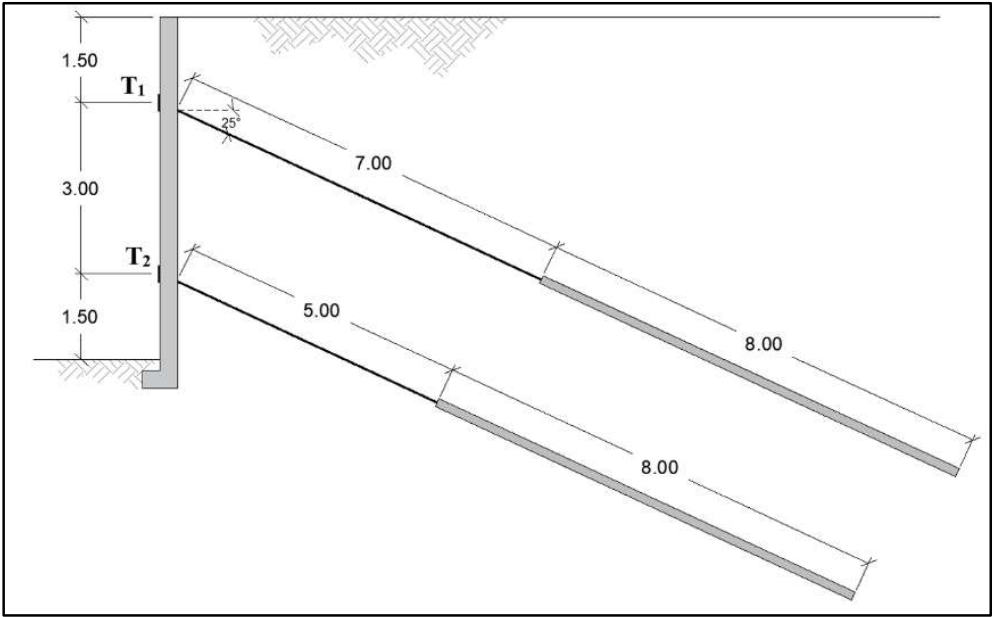

Figura 9: Espaçamentos adotados para os tirantes.

A Tabela 2 apresenta um resumo das informações dos tirantes.

Tabela 2: Espaçamentos adotados para os tirantes.

\begin{tabular}{lllll}
\hline & $\mathrm{LI}(\mathrm{m})$ & $\mathrm{La}(\mathrm{m})$ & $\emptyset(\mathrm{mm})$ & Carga de trabalho $(\mathrm{kN})$ \\
\hline $\mathrm{T} 1$ & 7 & 8 & 32 & 350 \\
\hline $\mathrm{T} 2$ & 5 & 8 & 32 & 350 \\
\hline
\end{tabular}

\section{Análises de Estabilidade}

Com intuito de diminuir os esforços sobre a cortina de concreto, optou-se por diminuir a ficha o máximo possível, de forma que ainda atendesse as condições de estabilidade interna e externa. Isso foi feito com auxílio do módulo 'Verificação de contenção' do software GEO5, por meio de tentativa e erro. A Figura 10 apresenta o comprimento mínimo necessário encontrado pelo software $(6,40 \mathrm{~m})$, assim como os diagramas de momento fletor e força cisalhante. A força no tirante utilizada nas análises foi de $218,75 \mathrm{kN}$ $(350 / 1,6)$, uma vez que o software considera força por metro, sendo o espaçamento entre as ancoragens igual $1,6 \mathrm{~m}$.

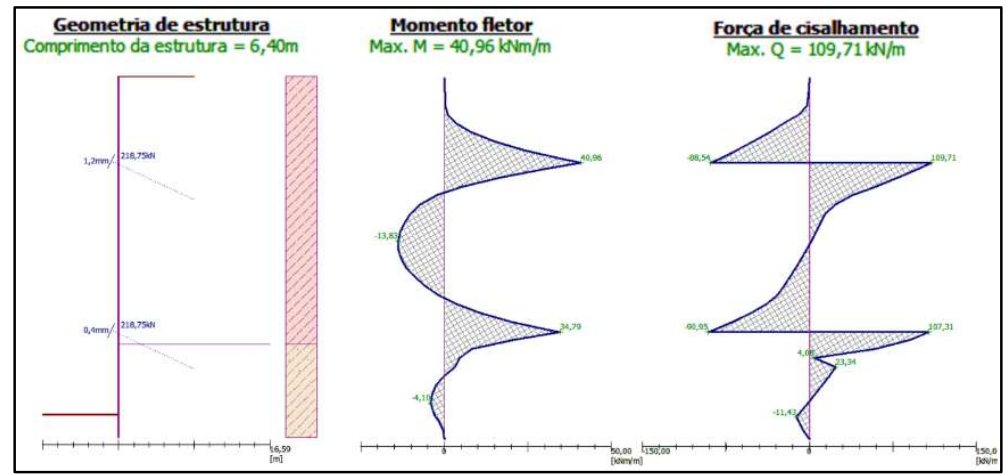

Figura 10: Comprimento mínimo da ficha e esforços internos na cortina. 
Nessa mesma análise, ainda foram obtidos os deslocamentos e a distribuição de tensões agindo sobre a cortina (Figura 11). Observa-se que o diagrama de distribuição de empuxos não apresenta mais o formato triangular adotado nas teorias clássicas (Rankine e Coulomb), isso se deve ao fato da cortina não apresentar mais o padrão de deslocamentos que satisfaça as hipóteses adotadas por essas teorias.

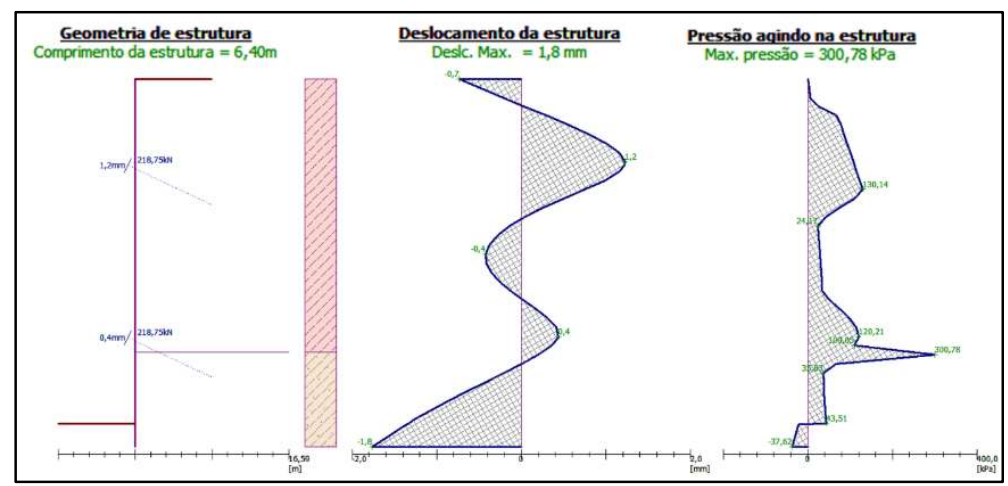

Figura 11: Deslocamentos e a distribuição de tensões agindo na cortina.

Foram realizadas duas análises de estabilidade externa no software utilizando o método de Bishop. A primeira sem a consideração dos tirantes apresentou fator de segurança $F S=1,25$, inferior a 1,5 permitido pela norma (Figura 12). Foi possível observar, também, que os bulbos de ancoragem se encontram além da superfície crítica, sendo, desta forma, o valor do comprimento livre adotado suficiente.

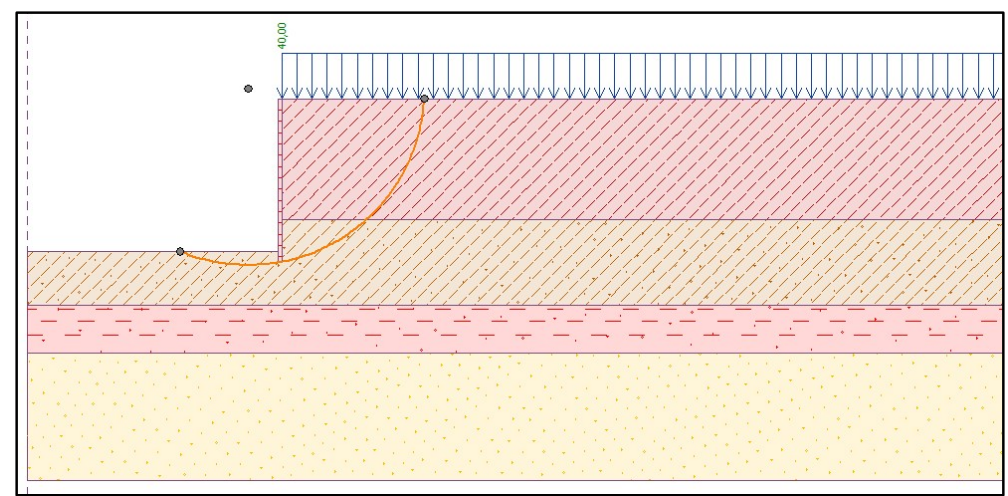

Figura 12: Superfície de deslizamento crítica (sem os tirantes).

Na segunda análise, com a introdução das forças de protensão dos tirantes (350 kN), o fator de segurança obtido foi FS=1,8 (>1,5) (Figura 13). Nas duas análises foi utilizada a sobrecarga de 40kN. A Tabela 3 apresenta os resultados detalhados fornecidos pelo software.

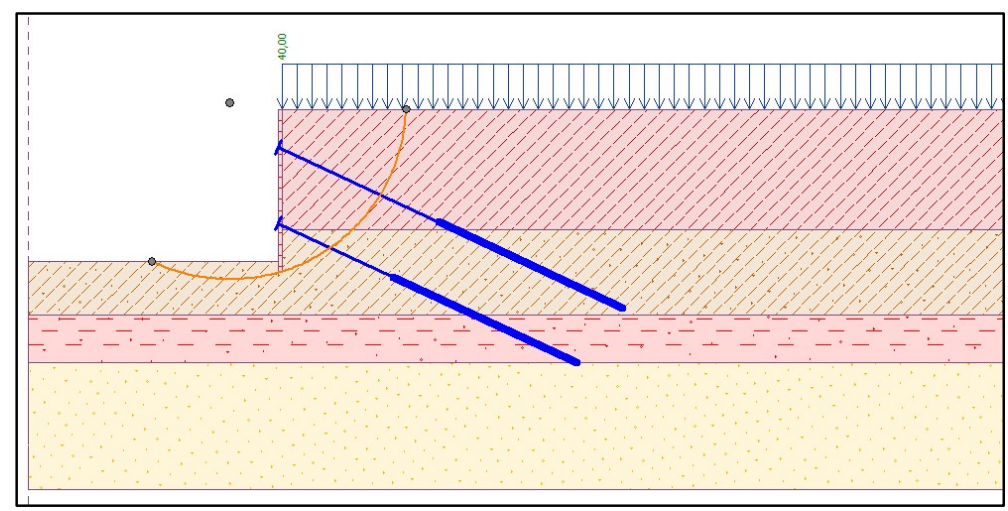

Figura 13: Superfície de deslizamento crítica (com os tirantes). 
Tabela 3: Verificação da estabilidade externa (Bishop).

\begin{tabular}{lll}
\hline & Sem os tirantes & Com os tirantes \\
\hline Soma das forças ativas $(\mathrm{kN} / \mathrm{m})$ & 394,91 & 381,92 \\
\hline Soma das formas passivas $(\mathrm{kN} / \mathrm{m})$ & 491,89 & 688,47 \\
\hline Momento de deslizamento $(\mathrm{kN} . \mathrm{m} / \mathrm{m})$ & 2736,71 & 2662,00 \\
\hline Momento de resistência $(\mathrm{kN} \cdot \mathrm{m} / \mathrm{m})$ & 3408,81 & 4798,65 \\
\hline Fator de Segurança & 1,25 & 1,80 \\
\hline
\end{tabular}

As cunhas analisadas para a estabilidade interna da primeira e segunda linha de tirantes podem ser visualizadas nas Figuras 14 e 15. A Tabela 4 apresenta os resultados computados pelo software.

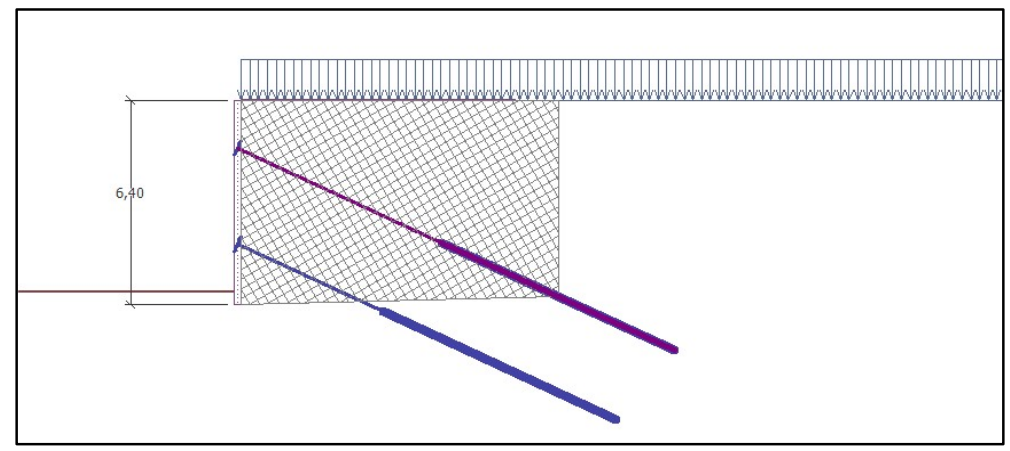

Figura 14: Cunha para análise de estabilidade interna da primeira linha de tirantes.

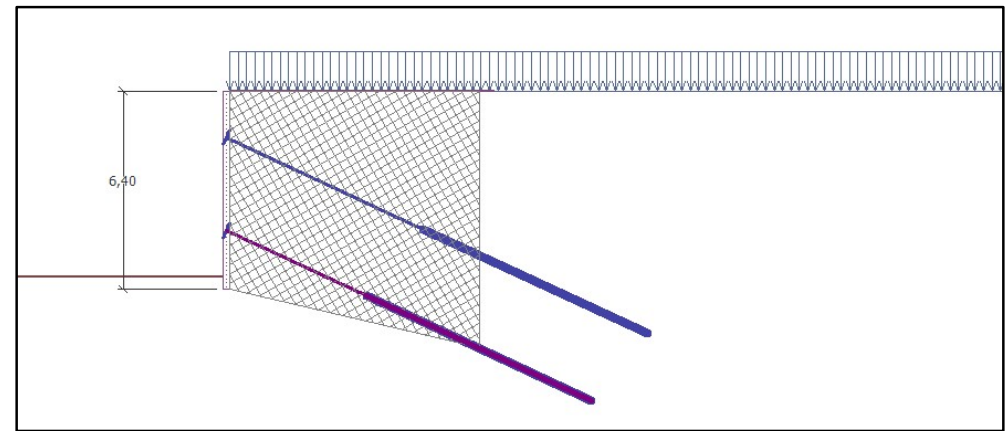

Figura 15: Cunha para análise de estabilidade interna da segunda linha de tirantes.

Tabela 4: Resultados da análise de estabilidade interna das ancoragens.

\begin{tabular}{lll}
\hline & Primeira linha & Segunda linha \\
\hline Força na ancoragem & 218,75 & 218,75 \\
\hline Máxima força permitida na ancoragem & 514,25 & 944,22 \\
\hline Fator de segurança & 2,35 & 4,32 \\
\hline
\end{tabular}

\section{CONCLUSÕES}

O presente trabalho apresenta uma solução de contenção para um talude de corte executado para a implantação de um subsolo. Após um estudo preliminar dos tipos de contenção, foi escolhido cortina atirantada como solução tecnicamente viável.

A força de ancoragem, encontrada pelo software GEO5 pelo método de base livre, foi de 350kN. Para atender a esta carga de trabalho, adotando tirante tipo manobarra com tensão de escoamento de $85 \mathrm{t} / \mathrm{mm}^{2}$, o diâmetro solicitado foi de $32 \mathrm{~mm}$.

Quanto às análises de verificação de estabilidade realizadas, o fator de segurança encontrado para estabilidade global foi de 1,80, e para estabilidade interna o fator de segurança decisivo foi de 2,35, ambos acima de 1,5 exigido pela NBR 11682 (ABNT, 2009).

Neste trabalho, pretendeu-se descrever todos os passos que conduziram à adoção da solução 
apresentada. Desta forma, foi possível fazer uma análise mais aprofundada dos métodos que conduzem ao dimensionamento geotécnico deste tipo de estruturas.

\section{REFERÊNCIAS}

ABNT. Associação Brasileira de Normas Técnicas. NBR 6118: Projeto de estruturas de concreto - procedimento. Rio de Janeiro: ABNT, 2014.

ABNT. Associação Brasileira de Normas Técnicas. NBR 6122: Projeto e execução de fundações. Rio de Janeiro: ABNT, 2010.

ABNT. Associação Brasileira de Normas Técnicas. NBR 11682: Estabilidade de encostas. Rio de Janeiro: ABNT, 2009.

ABNT. Associação Brasileira de Normas Técnicas. NBR 5929: Execução de tirantes ancorados no terreno. Rio de Janeiro: ABNT, 2006.

BARROS, P. L. A.. Obras de contenção: Manual técnico. Jundiaí: Maccaferri do Brasil, 2008.

BOWLES, J. E.. Foundation analysis and design. 3 ed. Nova lorque: McGraw-Hill, 1982.

DUTRA, V. A. S.. Projeto de estabilização de taludes e estruturas de contenção englobando dimensionamento geotécnico e estrutural. Rio de Janeiro: Universidade Federal do Rio de Janeiro, 2013.

GEORIO. Manual Técnico de Encostas. 2 ed. Rio de Janeiro: GEORIO, 2014.

GERSCOVICH, D.; DANZIGER, B. R.; SARAMAGO, R.. Contenção: teoria e aplicações em obra. São Paulo: Oficina de textos, 2016.

GERSCOVICH, D. M. S.. Empuxos de terra. Rio de Janeiro: Universidade do Estado do Rio de janeiro, 2010.

JOPPERT JUNIOR, I.. Fundações e contenções em edifícios: qualidade total na gestão do projeto e execução. São Paulo: PINI, 2007.

LUIZ, B. J.. Projeto geotécnico de uma estrutura de contenção em concreto. Monografia (Bacharelado) Universidade Federal do Rio de Janeiro, Rio de Janeiro, 2014.
MACHADO, A. X.; MENDES, L. C.. Influência ao longo do tempo de sobrecargas adicionais devido a novas construções informais sobre obras de contenção de encostas em cortina ancorada em comunidades na cidade do Rio de Janeiro. In: CONGRESSO BRASILEIRO DE PONTES E ESTRUTURAS, 9. Anais. Rio de Janeiro, 2016.

MAGALHÃES, M. S.. Dimensionamento de estruturas de contenção atirantadas utilizando os métodos de equilíbrio limite e de elementos finitos. Dissertação (Mestrado em Engenharia Civil) - Pontifícia Universidade Católica, Rio de Janeiro, 2015.

MASSAD, F.. Obras de Terra: curso básico de Geotecnia. 2 ed. São Paulo: Oficina de Textos, 2010.

MOLITERNO, A.. Caderno de Muros de Arrimo. São Paulo: Edgard Blücher, 1980.

MOTA, R. J.. Análise da interação solo-estrutura de uma obra de contenção na cidade de Goiânia-GO. Dissertação (Mestrado em Engenharia Civil e Ambiental) - Universidade de Brasília, Brasília, 2008.

PRADO, N. M. P.. Projecto da estrutura de suporte de uma escavação para um grande edifício no porto. Dissertação (Mestrado em Engenharia Civil) - Faculdade de Engenharia da Universidade do Porto, Porto, 2008.

SCHNAID, F.; ODEBRECHT, E.. Ensaios de Campo e suas aplicações à Engenharias de fundações. 2 ed. São Paulo: Oficina de textos, 2012.

SILVA, J. P. M.. Os métodos de equilíbrio limite e dos elementos finitos na análise de estabilidade de taludes. Dissertação (Mestrado em Engenharia Civil) - Faculdade de Engenharia da Universidade do Porto, Porto, 2011.

TURCARELLI, T.. Aspectos de projeto, execução e comportamento de cortinas atirantadas. Monografia (Bacharelado em Engenharia Civil) - Universidade Federal de São Carlos, São Carlos, 2013.

A CBPC - Companhia Brasileira de Produção Científica (CNPJ: 11.221.422/0001-03) detém os direitos materiais desta publicação. Os direitos referem-se à publicação do trabalho em qualquer parte do mundo, incluindo os direitos às renovações, expansões e disseminaç̃oses da contribuição, bem como outros direitos subsidiários. Todos os trabalhos publicados eletronicamente poderão posteriormente ser publicados em coletâneas impressas sob coordenação da Sustenere Publishing, da Companhia Brasileira de Produção Científica e seus parceiros autorizados. Os (as) autores (as) preservam os direitos autorais, mas não têm permissão para a publicação da contribuição em outro meio, impresso ou digital, em português ou em tradução. 